\title{
A Scientific Novel Way of Article and Thesis Writing: Findings from a Survey on Keyword, Sequence, and Importance (KSI) Technique
}

\author{
Md Kamal Uddin ${ }^{1, *}$, Md Uzir Hossain Uzir², Md. Mahadhi Hasan ${ }^{3}$, Mohammad Salim Hassan ${ }^{1}$, \\ Mohammad Sahabuddin ${ }^{4}$ \\ ${ }^{1}$ Faculty of Agriculture, Universiti Putra Malaysia (UPM), 43400, UPM Serdang, Selangor, Malaysia \\ ${ }^{2}$ Department of Marketing, Putra Business School, Serdang, Selangor, Malaysia \\ ${ }^{3}$ Department of English, Southeast University, Dhaka, Bangladesh \\ ${ }^{4}$ School of Business and Economics, Universiti Putra Malaysia, 43400, UPM Serdang, Selangor, Malaysia
}

Received September 24, 2020; Revised November 20, 2020; Accepted November 29, 2020

\section{Cite This Paper in the following Citation Styles}

(a): [1] Md Kamal Uddin, Md Uzir Hossain Uzir, Md. Mahadhi Hasan, Mohammad Salim Hassan, Mohammad Sahabuddin, "A Scientific Novel Way of Article and Thesis Writing: Findings from a Survey on Keyword, Sequence, and Importance (KSI) Technique," Universal Journal of Educational Research, Vol. 8, No. 12A, pp. 7894-7904, 2020. DOI: 10.13189/ujer.2020.082578.

(b): Md Kamal Uddin, Md Uzir Hossain Uzir, Md. Mahadhi Hasan, Mohammad Salim Hassan, Mohammad Sahabuddin (2020). A Scientific Novel Way of Article and Thesis Writing: Findings from a Survey on Keyword, Sequence, and Importance (KSI) Technique. Universal Journal of Educational Research, 8(12A), 7894-7904. DOI: 10.13189/ujer.2020.082578.

Copyright $\mathrm{C} 2020$ by authors, all rights reserved. Authors agree that this article remains permanently open access under the terms of the Creative Commons Attribution License 4.0 International License

\begin{abstract}
Academic scientific writing is essential to graduation and post-graduation. Many graduate students suffer from a lack of systematic technique. An effective and efficient writing skill and technique guide the students to produce a good article and thesis in a short period. Keyword, Sequence, and Importance (KSI) is a robust academic writing technique. The study investigated the KSI model's effectiveness in academic writing using the knowledge, attitude, and practice (KAP) model. The authors of articles and dissertations are sometimes in a fix on how to start, how to flow, how many citations are needed, how many words to be included in a paragraph, which should come first, and the sequence, etc. A total of 55 students (Ph.D., Masters, and others), who participated in the workshop to learn the KSI model in the workshop, participated in this study, and provided necessary data. SPSS statistical tool was used to analyze the collected data to examine KAP's impact on authors' writing performance. The results of multiple regression showed that attitude and practice had a significant effect on scientific writing performance. The findings implicate that the KSI model is a persuasive writing technique with which the supervisors can adequately guide their students. The students can
\end{abstract}

produce scientific writing in a minimum time. The KSI model, practically, benefits a student to get graduate on time (GOT). The study findings also contribute to the KAP model to support its theoretical assumptions in the education sector.

Keywords Keywords, Sequence, Importance, Knowledge, Attitude, Performance, Practices, Universiti Putra Malaysia

\section{Introduction}

Postgraduate thesis writing proves to be challenging for most of the graduate students. They may carry out research with ease but writing the research documents as a thesis seems to be constrained to most students. More often than not, a postgraduate student will naturally be in a dilemma about putting things together in writing the thesis $[1,2]$. This leads to a failure to complete the thesis within the stipulated time. The problems extend across disciplinary boundaries and are almost common to postgraduate 
research in both social and natural sciences [3]. Therefore, the reasons why graduate students failed to complete their theses within the specified period include the slow formulation of the problem and literature survey; meticulousness of students who are never satisfied with their work; a distraction from the main focus of the research project (for example, by reading texts unrelated to the topic); and inadequate collection of data due to poor planning.

The thesis writing difficulties will be eliminated when certain skills are provided to graduate students at the beginning of their programs. The training will remove the misconceptions and uncertainties in the mind of new students and prepare them on how to write clearly and precisely. It is argued that one approach which can assist the student in overcoming these problems is the workshop; research skills can be developed through practical guidance, group-support, discussion, and reflection, which occur in the workshop context [4]. The Keyword Sequence Importance (KSI) is a new model to provide students with a clear approach to thesis writing that will yield high-quality text in a short period. In this system, major keywords are identified based on the story of the subject, treatment, parameter for science research and respondent, independent variable and dependent variable for social science research. These keywords are then organized on their preference and importance, while the fraction of their contents is included based on their relative importance. The program features the development of students immense skill toward thorough scientific writing, aiding them to familiarize themselves with scientific research methodology and instil their understanding of scientific innovation. The training for new students about this effective writing skill from the beginning to their postgraduate program will surely equip students with the ability to produce a better quality thesis and a high probability of completing their program time.

Torrance et al. [5] focus on three different methods: product-centred, cognitive, and general writing courses for postgraduate students on thesis writing. Their findings show the benefit of teaching research writing to graduate students. However, they focus only on generating text instead of strategies for generating ideas before writing the thesis. The KSI is a systematic approach to selecting the thesis keywords, arranging it in chronological order of significance, and keeping the volume of each keyword according to its importance on the chosen topic. Generally, the thesis keywords characterize the words or phrases used to identify the subject's primary significance, so it is the backbone of any meaningful scientific writing. Thus, the present tool is going to provide a standard platform for students coming from different fields of studies as a first-hand guide to achieving the target of postgraduate schools (i.e., graduation on time). The technique has several advantages: fast problem formulation, comprehensive literature review, rapid publication, good quality thesis, mental stress elimination, and graduation on time. The article targets solving two issues: student and supervisor tasks on defining the research problem and the planning aspect of the thesis writing. The systematic collection of words and phrases will help improve the linguistics part of the thesis while maintaining the standard and quality of the write-up. The paper aimed to improve the quality of the postgraduate thesis, enable fast publication, reduce mental stress associated with the postgraduate degree, and provide a platform for graduation on time.

\section{Literature}

\section{KSI Model and its Usage}

The KSI technique is applicable for thesis writing in all fields of study, including engineering, social sciences, medical sciences, agriculture, etc. The KSI technique identifies all the keywords from the thesis title and arranges them in sequence based on their importance or relevance. The most important keyword comes first, followed by the second most important keyword, followed by the third most important keyword. For instance, given the thesis title 'Salinity effect on the growth, antioxidant and mineral compositions of Purslane', the primary keywords according to the sequence of subject matter, treatment and parameters are as follows: Purslane, salinity, and growth, antioxidant and mineral compositions. Thus, the researcher can simply use these keywords in the sequence of their importance in writing all chapters of his/her thesis. KSI model also enlisted an effective and widely used word bank that would help the author to use the alternative word. Since English is a foreign language for many countries and many authors; thus, vocabulary knowledge is very important for scientific and academic writing [6].

\section{Standard ratio/ importance for science and social science}

Science research consists of subject matter, treatment (s) and parameters. The standard importance ratio of subject matter, treatment and parameter is 1:3:6 or 1:2:7, respectively. Social science research consists of subject matter, the independent variable (s), and dependent variables. The standard importance ratio of subject matter, the independent variable (s), and dependent variables are $1: 4: 5$ or $2: 3: 5$, respectively.

\section{General Introduction}

The general introduction can be easily prepared when using the KSI technique appropriately using the formula:

Required page number for each keyword $=\frac{\text { Target page number X Importance percentage }}{100}$

Required citation number for each keyword = Citation number per page $\times$ required page number. 
The preparation of a general introduction consists of five pages. The number of target pages and keywords is five; thus, each keyword is getting tentatively one page, but it is not proper because every keyword does not have equal importance for the introduction. However, the accurate way of doing it is to make each keyword's volume based on its relevancy to make the presentation more qualitative and precise. Table 2 illustrates how volume was assigned to each keyword based on its impact on the thesis objectives; Purslane (10\%), Salinity (30\%), growth (10\%), antioxidant $(30 \%)$, and mineral compositions $(20 \%)$. This clearly demonstrates that both the target plant (Purslane) and the growth require only general information. However, the treatment (salinity) and the antioxidant effects have been the two major significant research factors that need much volume for proper clarification. Moreover, the Purslane has a 0.5 page equivalent to $10 \%$ of the total number of pages required for the general introduction. Similarly, the page numbers for other keywords are calculated based on their percent contributions. The target number of citations must also be carried out according to the number of pages assigned to each keyword; for example, the number of citations required for a half-page should not be more than four, while 1.5 pages are necessary for a maximum number of 12 citations. Similarly, the priority of the citation set-up should be according to the importance of the information.

Hence, the problem statement and research objectives can also be formulated using the keywords summary. The keywords contain basic ideas on the research problems, their importance, and the possible way of solving the problems. In this case, how does salinity affect the growth, antioxidant and mineral compositions of the Purslane plant? The literature review might partially answer the questions, and this will give a hint on how to proceed with the research.

\section{Literature Review}

Initially, the number of pages for the literature review is to be decided according to each keyword size. Subsequently, the heading and sub-headings for each keyword should be prepared before the beginning of the data collection. Also, the keywords sequence and the number of required citations for each keyword should be initially set. Finally, the target citation can be added to the appropriate sub-headings for each keyword. For instance, the preparation of 25-page literature review using the sequence and size of the keywords will provide the volume of each keyword as follows; $10 \%, 30 \%, 10 \%$, $30 \%$, and $20 \%$ for Purslane, Salinity, growth, antioxidant, and mineral compositions, respectively. However, the number of pages might increase or decrease tentatively, but the target number of citations should be maintained. The literature review is considered the most significant aspect of any thesis, and when it is done early, the researcher will become more conversant with the work. The benefits of using the KSI technique to prepare the literature review include; reduction of mental stress and achieving target pages within a short period.

\section{Materials and Methods}

The methods of data collection and experimental procedures must be outlined explicitly with proper reference. The beginning of the methodology will be about data collection location, while the last task will be the statistical analysis.

\section{Result and Discussion}

The parameter legends, first sentence, table legends, and dummy table for each experiment should be prepared before conducting the experiment. Because all the parameters need their separate legend, first sentences, and tables for the presentation of results and discussion, preparing it earlier will save the student time during the thesis writing. It is advised that after getting results, the student has to focus on writing two to three parameters correctly. After that, the student has to edit the written draft and submit it to the supervisor for correction and improvement. For the rest of the parameters, the researcher is advised to follow the same writing style as in the approved draft. Based on this technique, the student is expected to save time, reduce mental stress, establish coherence, and sustain the quality of the work from the beginning. Finally, 3 to 4 related citations should be added after the dummy table for each parameter.

\section{Dummy Table of Each Experiment}

The student is expected to prepare a dummy table for displaying his research results. For example, if the study has twenty parameters, the student is supposed to make twenty dummy tables. The preference is given to the use of a table than figures when writing the result section of each parameter because of a clear visual impression. However, the student can later convert some possible parameters into pictures to guide the reader in interpreting the results apparently.

\section{Discussion Set-up of Each Experiment}

The student is advised to have an advanced collection of current citations (five years back) under each parameter. The collection goes simultaneously with paraphrasing and improvement before storing it at the established citation bank. From the citation bank, the paraphrased citation is transferred to the result section under each specific parameter. The student needs to prove his new findings using two to three citations that are already established in the citation bank. This advanced citation collection is expected to save time, reduce mental stress, and maintain the quality of the work. The discussion could be prepared according to the following steps:

i). Discussion part typically should move from specific to general (opposite of introduction) 
ii). Often should begin with a brief summary of the significant findings

iii). Should interpret results clearly and concisely with Biological/Science/Social factor mechanisms (why, how)

iv). Should relate literature results with other research findings. Are they consistent? If not, discuss possible reasons for the difference.

v). Should answer the question(s) stated in the introduction (problem statement part)

vi). Commonly should note the strengths and limitations of the study

vii). May identify other research needed.

\section{Conclusion of Each Experiment}

This section has to be connected to each objective of the given experiment. This means the conclusion of each experiment has to be similar to the experiment title and its aim. The purpose is to maintain coherence, give the natural sense of completeness, follow the sequence, and engage the reader. Lastly, the researcher or student is expected to provide one concluding statement. This can be done by consulting different related scientific journals and paraphrasing accordingly.

\section{Summary and Conclusion}

The student is advised to select the main parameters for each of the experiments conducted. For instance, if each experiment has twenty parameters, then the student or researcher can choose at least $40-50 \%$ consistent with the objective and the established sequence. From the citation bank, the student is expected to select another three new citations different from the previous ones used in the experimental discussion part to make the whole thesis more vibrant. Furthermore, in writing the summary section, the sequence of the results for each parameter should be maintained. Finally, the last paragraph has to focus on the general recommendations and future research suggestions based on the research findings.

\section{Steps to Prepare a Summary and Conclusion}

Paragraph 1: "Reason for performing the study" perspective for readers to remind them of the importance of your study. Paragraph 2: A critical analysis of your major finding(s). Paragraph 3: Explain the meaning of the findings and why the findings are important. Paragraph 4: Relate the findings to those of similar studies. Paragraph 5: Consider alternative explanations of the findings. Paragraph 6: Acknowledge the limitations of the study. Paragraph 7: Make suggestions for future research. Paragraph 8: Overall conclusion and the major impact of your study.

\footnotetext{
Abstract

The abstract should be prepared according to primary fundamental issues like an introductory sentence, a
}

combination of the objectives, a concise method, the main findings of all the goals, and finally, the recommendation. The whole section has to be written in one paragraph without any citation.

\section{Hypothesis Development:}

Sadhu and Kotwal [7] studied the Knowledge-Attitude-Practice study on nutrition education of athletic and non-athletic teenagers. A sufficient amount of food is essential throughout infancy, but it is most important during juvenility. Sadhu and Kotwal [7] asserted that there was a moderate to a high level of awareness regarding nutrition-related perspectives before trainin. After training, there was a significant increase with a high level of awareness among the majority. However, Sadhu and Kotwal [7] found positive change and suggested that workshops and courses will foster teenagers' nutritional knowledge, attitudes, and practices.

Moreover, Wan et al. [8] quested a systematic review of the KAP-O framework for diabetes education and research. Diabetes self-control programs upheld the necessity to ameliorate knowledge, attitude, and practice of self-care. Wan et al. [8] emphasized four causally specified conjectures- knowledge, attitude, practice, and outcome. They found the positive outcome of health education interventions on all four conjectures. Wan et al. [8] suggested further study to determine if knowledge or attitude has a more prevalent impact on preventive practice and, thus, on diabetes care outcome.

Also, Roelens et al. [9] experimented with a knowledge, attitude, and practice survey among obstetrician-gynaecologists on intimate partner violence. Intimate Partner Violence (IPV) is deliberated as a leading cause of physical injury, mental distress, along with hostile pregnancy results. Roelens et al. [9] endeavored to find out potential constraints to IPV screening. They found a very poor number of respondents who ever received any instruction on IPV. Roelens et al. [9] suggested physician training endorsement for successful screening guidelines for IPV. They also added that screening tools, patient leaflets, etc., can also be important for advanced screening and guidelines.

Bano et al. [10] found that nutrition students possess significantly more improved knowledge, attitude and practice towards a balanced diet than non-nutrition students. Appropriate diet knowledge of the students has a considerable effect on promoting a society's health since students are the main constituent of families and professionals in every society and represent the future parents. Therefore, Bano et al. [10] emphasize having an adequate diet, regular physical activity, never skipping breakfast, including nutrition courses in the curriculum, reading food labels and counting daily calorie intake, etc., to enhance students' nutrition behavior.

The research report (Gender in Education: Knowledge, Attitude and Practice (KAP) Assessment) claimed gender 
disparity in the education sector of Pakistan to be highly unsatisfactory compared to other countries. Some detectable sides of this disparity are enrolment rates, overall literacy rate of boys and girls, learning environment, basic facilities, school management, teaching \& learning practices of public sector schools, etc. To address the qualitative issues, Knowledge, Attitude and Practice (KAP) assessment has been exercised to implement the Gender in Education Policy Support Project (GEPSP). The assessment helped to identify three main points for improvement and capacity needs- (i) Enabling environment; (ii) Institutional/ organizational improvements \& (iii) Building capacities of individuals.

Another study by Matinhure [11] revealed the unveiling factors that create barriers for parents in HIV testing and treatment among children aged 0-14 years. Findings under KAP assessment blamed the low level of agreement and outcome expectancy, relatively low motivation, low self-efficacy, community and self-stigma, perceived unavailability of services, etc., as negative barriers towards HIV testing and treatment of children. In addition, Matinhure [11] upheld some statistics regarding parents' knowledge in HIV transmission among children, their attitude and the feasibility of getting their children tested for HIV and initiated for treatment. Moreover, some recommendations were suggested, such as the provision of skills, support to parents for HIV disclosure, reducing stigma, localized care, and improving service quality available to the children.

In addition, Wang et al. [12] explained the status of factors associated with residents' knowledge, attitudes, and practices (KAP) related to air pollution, and it is also correlated to the respiratory health of children in Shanghai. The purpose of this study was to utilize the facts to influence Chinese health policies. Wang et al. [12] conducted a cross-sectional survey and evaluated Shanghai resident's KAP of air pollution. However, Wang et al. [12] further suggested allocating more resources towards educating citizens about it and providing them with appropriate practices to minimize the deleterious effects on their families. Whereas, Abdul et al. [13] suggested that there is a significant relationship among the variables like the brand name of the university, offered programs, permanent residence, fees, guardians' decision, and quality of education.

Akpeh and Ezeoke [14] highlighted the knowledge, attitude and behaviour of dispersion of flood alert campaigns in Anambra State in this discussion. The motive of this study was to discover how the flood disaster alert campaign dispersed among the residents of riverine communities. Akpeh and Ezeoke [14] stated that the respondents knew about the 2016 flood disaster alert. In addition, Akpeh and Ezeoke [14] explained that a high level of awareness did not significantly motivate the respondents to relocate. This study tackles to assess the success or otherwise of the campaigns in refinement and the residents of Anambra River basin to transpose. As per the extant literature review, the authors developed the following hypotheses:

$\mathrm{H}_{1}$ : Knowledge has a significant influence on performance.

$\mathrm{H}_{2}$ : Attitude has a significant influence on performance.

$\mathrm{H}_{3}$ : Practice has a significant influence on performance Model Development:

Performance $=\beta_{0}+\beta_{1} \mathrm{X}$ Knowledge $+\beta_{2} \mathrm{X}$ Attitude $+\beta_{3} \mathrm{X}$ Practice

The above regression model examines the effect of KAP on the scientific writing performance of the scholar after adopting the Keyword, Sequence and Importance (KSI) model.

\section{Methodology}

The study utilized a quantitative research method that involved the survey questionnaire design. In education research, three types of research are possible: exploratory design, explanatory design and descriptive design. This study conducted both explanatory research and descriptive research. The following section presented questionnaire development, measurement, and sampling method.

\section{Questionnaire Development and Measurement}

The study developed a questionnaire based on the study of Poorolajal et al. [15]. A total of 40 questions was generated to address knowledge, attitude, practices, and performance. In two sections of the questionnaire, the first section presented demographic information (Gender, Age, Academic status, etc. and the second section consisted of specific questions regarding the KSI model. The second section started with the status of the KSI model. Four variables: knowledge, attitude, practice and performance each included 10 statements (questions), and a total of 40 statements. These variables were measured on 5-point Likert Scale (' 1 ' indicates 'strongly disagree' and ' 5 ' indicates 'strongly agree'). The reliability of the questionnaire was within the range of threshold values. The value of Cronbach's alpha coefficient for the knowledge, attitude, practice and performance variables was $0.797,0.893,0.912$, and 0.925 , respectively above 0.70 , as shown in Table 1 [16].

Table 1. Reliability

\begin{tabular}{|c|c|c|}
\hline \multirow{2}{*}{ Variable } & \multicolumn{2}{|c|}{ Cronbach's Alpha } \\
\cline { 2 - 2 } & Individual & Overall \\
\hline Knowledge & 0.797 & \\
\hline Attitude & 0.893 & \multirow{2}{*}{0.967} \\
\hline Practice & 0.912 & \\
\hline Performance & 0.925 & \\
\hline
\end{tabular}

\section{Population}

The author conducted a workshop on Keyword, Sequence and Importance (KSI) model and scientific 
writing in June 2020 and earlier on the basis of knowledge, attitude, and practice (KAP) in Universiti Putra Malaysia (UPM), Malaysia. That workshop basically demonstrated the use of the KSI model in light of KAP theory. In those workshops, various students participated from faculties and universities. The participants were the population of this study. All attendants registered voluntarily and participated in those sessions. Data collection was collected from those attendants after completion of those sessions. 'The KSI model and scientific writing' is a registered course in Universiti Putra Malaysia. Students may take this course for their $\mathrm{PhD}$ and master level as coursework.

\section{Sample and Sampling Method:}

The study collected data from 55 students studying in various faculties of Universiti Putra Malaysia (UPM). From 11 faculties, a total of 55 respondents were interviewed. The data were collected from those students who participated in the workshop.

\section{Data Analysis and Result}

The study analyzed the data through the Statistical package for social sciences (SPSS). The following sections presented the demographic profile of the respondents, descriptive statistics, data normality, correlations, and multiple linear regression.

\section{Demographic Profile:}

As shown in Table 2, the respondents were $38 \%$ female and $62 \%$ male studying in various faculties in Universiti Putra Malaysia (UPM). Their age categories included 41\% with 25 years to 30 years; $29 \%$ were 30 to 35 years old. The respondents were equal in their master's degrees and doctoral degrees. More than $50 \%$ of respondents were in their respective second semester. In the second semester, many students started to understand the research. A total of $73 \%$ of respondents were from agriculture faculty. This workshop is conducted with the multinational respondents.

Table 2. Demographic Profile

\begin{tabular}{|c|c|c|c|}
\hline Characteristics & Particulars & Frequency & Percentage \\
\hline \multirow{2}{*}{ Gender } & Female & 21 & $38.18 \%$ \\
\hline & Male & 34 & $61.82 \%$ \\
\hline \multirow{4}{*}{ Age } & $25-30$ & 23 & $41.82 \%$ \\
\hline & $30-35$ & 16 & $29.09 \%$ \\
\hline & $35-40$ & 9 & $16.36 \%$ \\
\hline & Above 40 & 7 & $12.73 \%$ \\
\hline \multirow{2}{*}{ Education } & Masters & 28 & $50.91 \%$ \\
\hline & $\mathrm{PhD}$ & 27 & $49.09 \%$ \\
\hline \multirow{6}{*}{ Semester } & $1^{\text {st }}$ & 5 & $9.09 \%$ \\
\hline & $2^{\text {nd }}$ & 29 & $52.73 \%$ \\
\hline & $3^{\text {rd }}$ & 9 & $16.36 \%$ \\
\hline & $4^{\text {th }}$ & 6 & $10.91 \%$ \\
\hline & $5^{\text {th }}$ & 2 & $3.64 \%$ \\
\hline & $6^{\text {th }}$ & 4 & $7.27 \%$ \\
\hline \multirow{12}{*}{ Faculty and Department } & Agriculture & 40 & $72 \%$ \\
\hline & Design and architecture & 1 & $2 \%$ \\
\hline & English language & 1 & $2 \%$ \\
\hline & Environmental studies & 1 & $2 \%$ \\
\hline & Faculty of economics and management & 2 & $2 \%$ \\
\hline & Faculty of Educational Studies & 1 & $2 \%$ \\
\hline & Faculty of Veterinary Medicine & 1 & $2 \%$ \\
\hline & Human Ecology & 2 & $4 \%$ \\
\hline & Institute of Bioscience & 2 & $2 \%$ \\
\hline & Institute of Plantation Studies & 1 & $2 \%$ \\
\hline & IPPH & 1 & $2 \%$ \\
\hline & ITAFOS & 2 & $2 \%$ \\
\hline \multirow{2}{*}{ Marital Status } & Married & 41 & $74.55 \%$ \\
\hline & Unmarried & 14 & $25.45 \%$ \\
\hline \multirow{6}{*}{ Country } & Afghanistan & 10 & $18.52 \%$ \\
\hline & Bangladesh & 21 & $38.89 \%$ \\
\hline & Malaysia & 13 & $24.07 \%$ \\
\hline & Nigeria & 7 & $12.96 \%$ \\
\hline & Pakistan & 2 & $3.70 \%$ \\
\hline & Sri Lanka & 1 & $1.85 \%$ \\
\hline
\end{tabular}


A Scientific Novel Way of Article and Thesis Writing:

Findings from a Survey on Keyword, Sequence, and Importance (KSI) Technique

Table 3. Descriptive Analysis

\begin{tabular}{|c|c|c|c|c|c|c|c|}
\hline \multirow{2}{*}{ Statement } & \multirow{2}{*}{ Mean } & \multirow{2}{*}{$\mathrm{SD}$} & 1 & 2 & 3 & 4 & 5 \\
\hline & & & \multicolumn{5}{|c|}{ Percentage } \\
\hline \multicolumn{8}{|l|}{ Knowledge } \\
\hline 1. I have come to know elements of scientific research from the KSI Course. & 4.58 & 0.68 & 0 & 4 & 0 & 31 & 65 \\
\hline 2. KSI Model increases English language capability. & 4.15 & 0.67 & 0 & 2 & 11 & 58 & 29 \\
\hline 3. I get detailed information on thesis writing from KSI Model. & 4.56 & 0.56 & 0 & 0 & 4 & 36 & 60 \\
\hline 4. I learnt project report writing from KSI Model. & 4.27 & 0.65 & 0 & 2 & 5 & 56 & 36 \\
\hline 5. KSI model has increased knowledge regarding article writing & 4.55 & 0.68 & 2 & 0 & 0 & 38 & 60 \\
\hline 6. KSI course encompasses information of manuscript and article submission. & 4.60 & 0.53 & 0 & 0 & 2 & 36 & 62 \\
\hline 7. KSI Course provides detailed information on Book chapter writing. & 4.40 & 0.75 & 2 & 0 & 5 & 42 & 51 \\
\hline 8. This course gives an idea of the risk of plagiarism & 4.47 & 0.71 & 2 & 0 & 2 & 42 & 55 \\
\hline 9. KSI course provides an idea of conference attendance. & 4.07 & 0.73 & 0 & 2 & 18 & 51 & 29 \\
\hline 10. KSI Model standardizes citation techniques. & 4.51 & 0.60 & 0 & 0 & 5 & 38 & 56 \\
\hline \multicolumn{8}{|l|}{ Attitude } \\
\hline 1. I think KSI course teaches scientific research. & 4.51 & 0.54 & 0 & 0 & 2 & 45 & 53 \\
\hline 2. I think KSI course increases English language capability. & 4.18 & 0.72 & 0 & 2 & 13 & 51 & 35 \\
\hline 3. I think KSI course provides detailed information on thesis writing. & 4.58 & 0.56 & 0 & 0 & 4 & 35 & 62 \\
\hline 4. I think students learn from KSI Model how to write a project report. & 4.36 & 0.72 & 0 & 4 & 4 & 45 & 47 \\
\hline 5. I think KSI course gives a positive mind-set regarding article writing. & 4.49 & 0.54 & 0 & 0 & 2 & 47 & 51 \\
\hline 6. I think KSI course explains the process of developing a manuscript for a journal. & 4.47 & 0.57 & 0 & 0 & 4 & 45 & 51 \\
\hline 7. I think KSI Course provides detailed information on how to write a book chapter. & 4.38 & 0.59 & 0 & 0 & 5 & 51 & 44 \\
\hline 8. I think this course gives the idea of avoiding plagiarism (risk). & 4.56 & 0.56 & 0 & 0 & 4 & 36 & 60 \\
\hline 9. I think KSI course inspires us to participate in the conference. & 4.15 & 0.77 & 0 & 2 & 18 & 44 & 36 \\
\hline 10. I think KSI Model develops citation techniques. & 4.49 & 0.60 & 0 & 0 & 5 & 40 & 55 \\
\hline \multicolumn{8}{|l|}{ Practice } \\
\hline 1. I use the scientific research techniques from KSI Course. & 4.44 & 0.60 & 0 & 0 & 5 & 45 & 49 \\
\hline 2. I utilize KSI Model to increases English writing skills. & 4.22 & 0.62 & 0 & 0 & 11 & 56 & 33 \\
\hline 3. I use KSI technique to write a thesis. & 4.53 & 0.53 & 0 & 0 & 2 & 44 & 55 \\
\hline 4. I hope I will use KSI course outline to write the project report. & 4.49 & 0.60 & 0 & 0 & 5 & 40 & 55 \\
\hline 5. I properly use KSI model to publish articles. & 4.40 & 0.56 & 0 & 0 & 4 & 53 & 44 \\
\hline 6. I use KSI model to develop a complete manuscript for article submission. & 4.36 & 0.64 & 0 & 0 & 9 & 45 & 45 \\
\hline 7. I use KSI techniques to write book chapters. & 4.36 & 0.64 & 0 & 0 & 9 & 45 & 45 \\
\hline 8. I use KSI techniques to reduce plagiarism (or similarity). & 4.44 & 0.60 & 0 & 0 & 5 & 45 & 49 \\
\hline 9. I use KSI technique to attend conference performance effectively. & 3.98 & 0.80 & 2 & 0 & 22 & 51 & 25 \\
\hline 10. I use KSI techniques to make citations properly. & 4.40 & 0.56 & 0 & 0 & 4 & 53 & 44 \\
\hline \multicolumn{8}{|l|}{ Performance } \\
\hline 1. Scientific research techniques from KSI Course increase my knowledge. & 4.60 & 0.53 & 0 & 0 & 2 & 36 & 62 \\
\hline 2. KSI technique increases English writing capability. & 4.25 & 0.67 & 0 & 0 & 13 & 49 & 38 \\
\hline 3. I can write a thesis efficiently with KSI technique. & 4.55 & 0.53 & 0 & 0 & 2 & 42 & 56 \\
\hline 4. KSI technique increases my confidence in writing project report. & 4.51 & 0.54 & 0 & 0 & 2 & 45 & 53 \\
\hline 5. I am able to publish articles successfully. & 4.29 & 0.75 & 0 & 2 & 13 & 40 & 45 \\
\hline 6. I can develop a complete manuscript for article submission after learning KSI techniques. & 4.35 & 0.67 & 0 & 2 & 5 & 49 & 44 \\
\hline 7. KSI techniques help me write book chapters. & 4.29 & 0.68 & 0 & 0 & 13 & 45 & 42 \\
\hline 8. I am able to reduce plagiarism (or similarity). & 4.42 & 0.56 & 0 & 0 & 4 & 51 & 45 \\
\hline 9. I am able to present a paper at a conference. & 4.36 & 0.58 & 0 & 0 & 5 & 53 & 42 \\
\hline 10. I am able to use citations properly. & 4.44 & 0.56 & 0 & 0 & 4 & 49 & 47 \\
\hline
\end{tabular}

\section{Descriptive statistics:}

Table 3 summarized the four variable and their items. It was found that mean of the items was above 4 and the standard deviation was less than 1. Variable-wise their means were higher than 4.25 . and the standard deviation was less 
than 0.50 (Table 3). In the individual item scale, the maximum items took the value' 4' ('agree') and ' 5 ' ('strongly disagree').

\section{Data Normality:}

For multiple regression, data normality or normal distribution of collected data is a vital assumption [17]. Table 4 showed that skewness and kurtosis were between \pm 1.96 [18], which indicated data normality.

Table 4. Data Normality Test

\begin{tabular}{|c|c|c|c|c|}
\hline & Knowledge & Attitude & Practice & Performance \\
\hline Mean & 4.4164 & 4.4182 & 4.3618 & 4.4055 \\
\hline Std. Deviation & .39664 & .44767 & .46646 & .47742 \\
\hline Skewness & -.595 & -.351 & -.306 & -.215 \\
\hline Std. Error of Skewness & .322 & .322 & .322 & .322 \\
\hline Kurtosis & .397 & -.621 & -.916 & -1.103 \\
\hline Std. Error of Kurtosis & .634 & .634 & .634 & .634 \\
\hline
\end{tabular}

\section{Correlation:}

The correlation among knowledge, attitude, practice and performance was significant. As shown in Table 5, at 5\% significance level, the correlation coefficients were within 0.719 and 0.877 . It implied a higher positive correlation among the constructs. Their overall correlation coefficient was (R) 0.911 .

Table 5. Correlations

\begin{tabular}{|c|c|c|c|c|c|}
\hline & & Knowledge & Attitude & Practice & Performance \\
\hline \multirow{2}{*}{ Knowledge } & Pearson Correlation & 1 & $.834^{* *}$ & $.719^{* *}$ & $.771^{* *}$ \\
\hline & Sig. (2-tailed) & & .000 & .000 & .000 \\
\hline \multirow{2}{*}{ Attitude } & Pearson Correlation & & 1 & $.883^{* *}$ & $.885^{* *}$ \\
\hline & Sig. (2-tailed) & & & .000 & .000 \\
\hline \multirow{2}{*}{ Practice } & Pearson Correlation & & & 1 & $.877^{* *}$ \\
\hline & Sig. (2-tailed) & & & & .000 \\
\hline \multirow{2}{*}{ Performance } & Pearson Correlation & & & & 1 \\
\hline & Sig. (2-tailed) & & & & \\
\hline
\end{tabular}

\section{Multiple Linear Regression:}

After complying with the multiple linear regression assumptions, the study ran regression analysis. Model summary Table showed that $\mathrm{R}^{2}$ was 0.830 . It depicted that knowledge, attitude, and practice explained $83 \%$ variance of performance (Table 6).

Table 6. Model Summary

\begin{tabular}{|c|c|c|c|c|}
\hline Model & $\mathrm{R}$ & R Square & Adjusted R Square & Std. Error \\
\hline 1 & $.911^{\mathrm{a}}$ & .830 & .820 & .42367523 \\
\hline \multicolumn{5}{|c|}{ a. Predictors: (Constant), Practice, Knowledge, Attitude } \\
\hline \multicolumn{3}{|c|}{ b. Dependent Variable: Performance } \\
\hline
\end{tabular}

From the ANOVA table (Table 7), it was found that the F value was 83.27 and the p-value was 0.000 which is less than 0.05 and statistically significant. Thus, the model fits well (Table 7). 
Table 7. Model fit testing (ANOVA)

\begin{tabular}{|c|c|c|c|c|c|}
\hline \multicolumn{2}{|c|}{ Model } & Sum of Squares & Mean Square & F & Sig. \\
\hline \multirow{3}{*}{1} & Regression & 44.845 & 14.948 & 83.278 & $.000^{\mathrm{b}}$ \\
\cline { 2 - 6 } & Residual & 9.155 & .180 & & \\
\cline { 2 - 6 } & Total & 54.000 & & \\
\hline \multicolumn{2}{|l|}{ a. Dependent Variable: Performance } \\
\hline \multicolumn{2}{|l|}{ b. Predictors: (Constant), Practice, Knowledge, Attitude } \\
\hline
\end{tabular}

Table 8. Path Analysis and Coefficients

\begin{tabular}{|c|c|c|c|c|c|c|c|c|}
\hline & \multirow{2}{*}{ Model } & \multicolumn{2}{|c|}{ Unstandardized Coefficients } & \multirow{2}{*}{$\begin{array}{c}\begin{array}{c}\text { Standardized } \\
\text { Coefficients }\end{array} \\
\text { Beta }\end{array}$} & \multirow{2}{*}{$\mathrm{T}$} & \multirow{2}{*}{ Sig. } & \multicolumn{2}{|c|}{ Collinearity Statistics } \\
\hline & & B & Std. Error & & & & Tolerance & VIF \\
\hline \multirow{4}{*}{1} & (Constant) & -1.002 & .057 & & .000 & 1.000 & & \\
\hline & Knowledge & .134 & .105 & .134 & 1.282 & .206 & .304 & 3.294 \\
\hline & Attitude & .380 & .155 & .380 & 2.450 & .018 & .138 & 7.226 \\
\hline & Practice & .446 & .123 & .446 & 3.619 & .001 & .219 & 4.563 \\
\hline
\end{tabular}

As the regression model fits well, the study checked the coefficient Table 8. From this Table, it is found that attitude and practice are significant with performance as their $\mathrm{p}$-values were less than 0.05 (beta value $=0.380$ $\mathrm{p}$-value $=0.018$ and beta value $=0.446$ and $\mathrm{p}$-value $=$ 0.001 , respectively). Therefore, hypotheses 2 and 3 were accepted. It stated that attitude and practice have a significant and positive effect on performance. On the other hand, knowledge was found insignificant because the $\mathrm{p}$-value is higher than 0.05 ( $\mathrm{p}$-value $=0.206$ ). Thus, it implies knowledge has no significant relationship with performance. The first hypothesis is rejected.

Research model equation:

Performance $=\beta 0+\beta_{1} X$ Knowledge $+\beta_{2} X$ Attitude $+\beta_{3} X$ Practice

Tested equation:

Performance $=-1.002+0.380 *$ Attitude $+0.446 *$ Practice.

The study aimed to investigate the effect of knowledge, attitude and practice on the performance of students. The findings showed that the KSI model increases students' positive attitude to their performance to write scientific research as the second hypothesis is accepted with significance. Similarly, after taking the KSI model course, students developed their skills to write quality academic papers and thesis. This KSI model is more effective.

\section{Discussion}

The findings from the descriptive analysis showed that the audience displayed very high positivity. The average of their response was more than 4 in the survey which implied this KSI technique is very supportive and helpful.
Individual items scored more than 4 and each variable is also more than 4 . The correlation is also very high. This finding was consistent with the previous survey on this technique. The study findings showed that knowledge, attitude, practice, and performance were positively correlated. These positive correlations indicated that the researchers' or students' positivity towards the KSI course would help them perform better (good writing in the minimum time). From the model assessment, the findings showed that attitude and practice had a significant and positive effect on the performance of researchers and students. This model was taught in many universities and participants' comments were taken. The majority of the audience appreciated this technique. Particularly, according to the participants, this technique is helpful to the $\mathrm{PhD}$ and Master students and researchers. Conversely, some of the participants appraised this technique as an appropriate tool for paper writing and publications. Some of them claim this KSI technique helpful for natural scientists; on the other hand, some appreciated as helpful for all disciplines. They praised this technique for its clear guidance and calculative presentation. One participant stated that the KSI technique is an effective tool for young researchers and easy thesis writing.

In $\mathrm{PhD}$ or Master, researchers and students often suffer from a lack of quality and systematic writing. They often hover in what to write, how to write, what to start, and how to start. KSI model depicts action and activities at each stage of paper or thesis writings. This technique clearly explains how many references would be placed in each section, each page, or each paragraph. It also shows the way to minimize the similarity index issue in paper writing and thesis writing. Another important strength is its word bank. Alternative words and presentation style make writing easier. 
Particularly, using this technique students can saves time as well as complete their study in 'graduate on time' (GOT). Moreover, it reduces psychological pressures and helps to publish research papers in high indexed impact factor journals.

\section{Conclusions}

From the empirical perspective, after identifying the problems, the students were introduced to an approach in academic writing, namely the KSI approach. The time of thesis writing will be shortened when this method is used. Particularly, researchers and students of $\mathrm{PhD}$ or Master degree program will be benefited from a systematic way of writing their thesis or dissertation. Moreover, this technique clearly explains a scientific combination between action and activities at each stage of a paper and thesis writing. For example, researchers and students will get a clear idea of how many pages should be considered for their paper and thesis's satisfactory length and how many references would be placed in each section, each page, or each paragraph. The implications of this study provide fresh insights to students, researchers, academicians, and policy-makers of higher study education. They will get a comprehensive idea regarding the way of scientific writing of research paper, thesis, and dissertation, saving time and reducing psychological pressure. This is how the students will get help to graduate on time (GOT).

\section{Theoretical Implication}

The study utilized the KAP theory to support the assumptions of hypotheses. It revealed that knowledge, attitude, and practice contribute to the performance of any action, especially learning activities. In thesis writing, it is shown that the KSI model improves the quality of writing through knowledge of the model, attitude toward authors, and their writing practice.

\section{Practical Contribution}

The study also showed a significant role of the KSI model. Using the KSI model and technique author of the report and thesis can improve their writing quality, reducing plagiarism and cohesion. KSI model enhances academic writing and develops readability.

\section{Limitation}

This study was conducted with 55 respondents at University Putra Malaysia (UPM). Future researchers can apply this model to other students and researchers and academicians. The study used SPSS for multiple regression. Future studies can apply structural equation modelling (SEM) for predicting and testing the theory.

\section{REFERENCES}

[1] Brodin, E.M., "The Stifling Silence Around Scholarly Creativity In Doctoral Education: Experiences Of Students And Supervisors In Four Disciplines," Higher Education, Vol. 75, No. 4, Pp. 655-673, 2018.

[2] Jeyaraj, J.J., "It's A Jungle Out There: Challenges In Postgraduate Research Writing," Gema Online ${ }^{\circledR}$ Journal Of Language Studies, Vol. 18, No. 1, 2018.

[3] Welsh, J.M., "The First Year Of Postgraduate Research Study," University Of Surrey, Graduate, Eric, England, Pp. 63, 1979.

[4] Zuber-Skerritt, O. And N. Knight, "Problem Definition And Thesis Writing," Higher Education, Vol. 15, No. 1, Pp. 89-103, 1986.

[5] Torrance, M., G.V. Thomas, And E.J. Robinson, "Training In Thesis Writing: An Evaluation Of Three Conceptual Orientations," British Journal Of Educational Psychology, Vol. 63, No. 1, Pp. 170-184, 1993.

[6] Br, A. And V. Rajasekaran, "Improving Noun Hyponyms Using Select Ted Wordlist Through Wordnet: An Investigational Study," Universal Journal Of Educational Research, Vol. 7, No. 11, Pp. 2495-2500, 2019. Doi: 10.13189/Ujer.2019.071129

[7] Sadhu, A.R. And D. Kotwal, "Knowledge-Attitude-Practice (Kap) Study And Nutrition Education Of Athletic And Non-Athletic Teenagers (13-18 Years)," In Ergonomics In Caring For People, Springer. Pp. 73-82, 2018.

[8] Wan, T.T., K. Rav-Marathe, And S. Marathe, "A Systematic Review Of Kap-O Framework For Diabetes," Medical Research Archives, Vol. 3, No. 9, 2016.

[9] Roelens, K., Et Al., “A Knowledge, Attitudes, And Practice Survey Among Obstetrician-Gynaecologists On Intimate Partner Violence In Flanders, Belgium,” Bmc Public Health, Vol. 6, No. 1, Pp. 238, 2006. Doi: Https://Doi.Org/10.1186/1471-2458-6-238

[10] Bano, R., Et Al., "A Comparative Study Of Knowledge, Attitude, Practice Of Nutrition And Non-Nutrition Student Towards A Balanced Diet In Hail University," Iosr Journal Of Nursing And Health Science (Iosr-Jnhs), Vol. 2, No., Pp. 29-36, 2013.

[11] Matinhure, N., "Knowledge, Attitudes And Practices Among Parents Towards Human Immuno-Deficiency Virus (Hiv) Testing And Treatment For Children: The Case Of Addis Ababa, Ethiopia," University Of South Africa, Master, Pp. 120, 2013.

[12] Wang, Z. And J. Ye, "Querying Discriminative And Representative Samples For Batch Mode Active Learning," Acm Transactions On Knowledge Discovery From Data (Tkdd), Vol. 9, No. 3, Pp. 1-23, 2015.

[13] Abdul, M., Et Al., "An Approach To Understand The Internal Enrollment Criteria Of Students' For Higher Education In Private Universities Of Bangladesh," British Journal Of Education, Vol. 4, No. 12, Pp. 76-87, 2016. 
[14] Akpeh, C.E.U. And C.B. Ezeoke, "Knowledge, Attitude And Practice (Kap) Study Of Diffusion Of Flood Alert Campaign In Anambra State," International Journal Of Business And Management Invention, Vol. 6, No. 6, Pp. 64-74, 2017.

[15] Poorolajal, J., Et Al., "Construction Of Knowledge, Attitude And Practice Questionnaire For Assessing Plagiarism," Iranian Journal Of Public Health, Vol. 41, No. 11, Pp. 54, 2012.
[16] Cronbach, L.J., "Coefficient Alpha And The Internal Structure Of Tests," Psychometrika, Vol. 16, No. 3, Pp. 297-334, 1951.

[17] Larocca, R., "Reconciling Conflicting Gauss-Markov Conditions In The Classical Linear Regression Model," Political Analysis, Vol. 13, No. 2, Pp. 188-207, 2005. Doi: $10.2307 / 25791805$

[18] Cohen, J., "Statistical Power Analysis," Current Directions In Psychological Science, Vol. 1, No. 3, PP. 98-101, 1992. 